\section{(- OPEN ACCESS}

\title{
Remission of treatment-resistant depression with tardive akathisia with electroconvulsive therapy
}

\author{
Thanos Emmanuel ${ }^{\odot}$
}

Barts and The London School of Medicine and Dentistry, Queen Mary University of London, London, UK

\section{Correspondence to} Thanos Emmanuel, ha15472@qmul.ac.uk

Accepted 19 June 2019
Check for updates

(c) BMJ Publishing Group Limited 2019. Re-use permitted under CC BY-NC. No commercial re-use. See rights and permissions. Published by BMJ.

To cite: Emmanuel T. BMJ Case Rep 2019;12:e229714. doi:10.1136/bcr-2019229714

\section{SUMMARY}

This report presents a case of drug-induced severe tardive akathisia developing after the combination of a selective serotonin reuptake inhibitor and an antipsychotic, in a woman with severe major depression. The trial and combination of multiple medications is common practice in treatment-resistant patients with depression. With the increase in the prevalence of treatment-resistant depression, adverse effects of medication such as tardive akathisia are becoming more common. Tardive akathisia persists even after the withdrawal of the causative agent and is very challenging to treat. The patient did not respond to any standard medications indicated for drug-induced akathisia. As a result, the patient became suicidal and extremely distressed with all treatment options exhausted. Guidelines on the management of druginduced tardive akathisia are non-existent. This reflects the importance of this case study, which reveals the complete remission of both tardive akathisia and all the patient's depressive symptoms after electroconvulsive therapy . This report provides evidence of an established treatment intervention used in a new situation.

\section{BACKGROUND}

Major depression is a common and disabling disorder affecting $14.6 \%$ of the population over a lifetime. ${ }^{1}$ Most patients respond to antidepressant treatment but $10 \%$ to $30 \%$ exhibit treatment-resistant symptoms. ${ }^{2}$ This severely affects the patients' quality of life. Treatment-resistant depression is a challenging condition for physicians who try to use integrated therapeutic strategies to tackle it. These include combining antidepressants, switching antidepressants and augmentation with non-antidepressants such as antipsychotics or lithium. However, the practice of combining and adding new agents has potential risks involved, including severe adverse effects, such as drug-induced akathisia in this case.

Akathisia consists of subjective inner restlessness, the inability to remain seated, restless legs and the desire to move constantly. Evident objective motor phenomena occur such as rocking, shifting from foot to foot, stamping in place and pacing around. Akathisia is known to be induced by antipsychotics and more rarely by selective serotonin reuptake inhibitors (SSRIs). Cases of SSRI-induced akathisia have been reported in literature in recent years. ${ }^{3}$ Various pharmacological agents have been used to treat this condition, but widely accepted clinical guidelines are lacking. The incidence of this condition is increasing mainly due to the increase in the use of atypical antipsychotics and the concurrent use of antidepressants and antipsychotics as an augmenting agent in non-responsive depressed patients. Tardive akathisia is defined as akathisia that is unremitting even after the withdrawal of antipsychotics from the patient. This can have detrimental effects on the patient and can potentially lead to suicide, as seen in this case. Evidence on the management of tardive akathisia is absent in literature.

We report a case of tardive akathisia induced by the combination of an SSRI, escitalopram and an augmenting antipsychotic, olanzapine. This had significant negative implications on the patient's existing severe mental illness. The occurrence of both disorders caused unremitting and unbearable distress that lead to a rapid deterioration and suicidal impulses. This highlights the importance of considering medication risks when combining various psychiatric drugs. It is essential to increase awareness of the adverse effects and drug interactions that can occur with psychiatric drugs.

\section{CASE PRESENTATION}

A 57-year-old woman presented with symptoms of low mood, loss of interest, nervousness and anxiety. After several unresponsive trials of SSRIs (paroxetine, escitalopram) and serotonin and norepinephrine reuptake inhibitors (SNRIs; venlafaxine, duloxetine), she was diagnosed with treatment-resistant depression. Although her depressive symptoms and anxiety showed minimal improvement after the trial of these antidepressants, the patient did not have any suicidal thoughts at this point.

Subsequently, she was prescribed the antipsychotic agent, olanzapine, to augment the SSRI escitalopram. This combination of medications did improve her symptoms for several weeks. However, a few weeks later while on escitalopram and olanzapine, the patient suddenly developed severe restlessness, inability to sit down and had to constantly pace around to feel more at ease. This would last until late at night affecting her sleep. Symptoms continued for weeks and as a result the patient became exhausted, severely distressed and exhibited suicidal thoughts and actions. For this reason, the patient was admitted as an inpatient in a psychiatric ward. After several weeks of suffering, the objective motor symptoms and inner restlessness were attributed to tardive akathisia using the Barnes Akathisia Rating Scale. It is important to note that 
although the patient was depressed, she displayed important signs of akathisia. She expressed severe distress associated with a sense of inner restlessness. She also reported a strong desire to walk and pace around most of the time which was the only way she could alleviate her restlessness. This is a characteristic feature of akathisia and constitutes one of the criteria of the Barnes Akathisia Rating Scale. On observation, the patient was unable to remain seated and was constantly rocking from foot to foot. Consequently, the causative agents were withdrawn but her inner restlessness remained unaltered even after the withdrawal of both the antipsychotic and SSRI. The patient scored 5/5 on the Barnes Akathisia Rating Scale (severe akathisia). At this point, doctors where uncertain on how to proceed as literature provides minimal guidelines on how to tackle such cases. Meanwhile her symptoms were severe, and the patient was still suicidal.

Most of the medications suggested in literature for akathisia were tried such as, beta-blockers, benzodiazepines and anticholinergic agents, but none achieved an improvement of the patient's symptoms. The patient's tardive akathisia severely complicated her treatment-resistant depression. At this stage, physicians were left with no other evidence-based treatment options and decided to carry out a single-photon emission CT (SPECT) scan to exclude the differential diagnosis of Parkinson's disease.

It is therefore essential that all practitioners are aware and competent in promptly identifying and managing akathisia. Commonly, practitioners may be reluctant to diagnose akathisia, attributing symptoms of restlessness to the patient's anxiety. As a result, more medications are prescribed, and doses are increased leading to paradoxically negative effects. This process is repeated, creating a vicious cycle. The use of rating scales such as the Barnes Akathisia Rating Scale can help doctors make an early diagnosis and prevent complications.

\section{INVESTIGATIONS}

A SPECT scan was carried out after the unsuccessful withdrawal of the causative agents and the trial of several treatment options. The rationale behind this was to exclude Parkinson's disease, which can present with akathisia due to decreased dopamine receptor stimulation and subsequent imbalance between dopamine and 5-HT receptor stimulation. A dopamine transporter (DAT) scan was used to detect the presence of dopamine

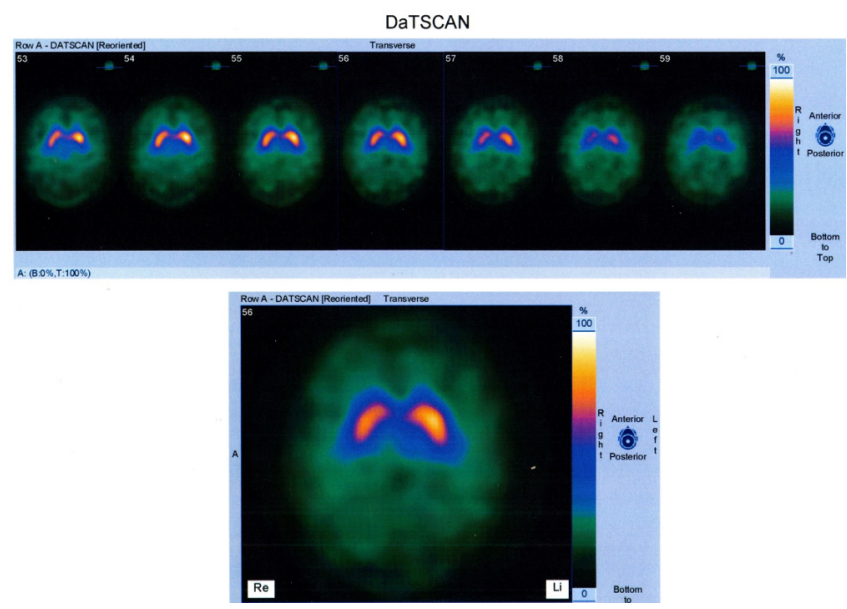

Figure 1 Single-photon emission CT after administration of DaTSCAN demonstrating normal dopamine uptake in presynaptic dopamine receptors of the basal ganglia. transporters in the brain. The scan results shown in figure 1 indicate the physiological uptake of dopamine via the transporters, hence Parkinson's disease was excluded.

\section{DIFFERENTIAL DIAGNOSIS}

When patients present with restlessness and agitation, anxiety is the most likely differential in most physicians' minds. However, the possibility of the subjectively distressing condition called 'akathisia' should always be considered. Akathisia should be screened for by checking any akathisia-inducing medication prescribed. Various medications used in general medical settings can induce akathisia, such as, metoclopramide, azithromycin, SSRIs and antipsychotics.

Antipsychotics use can cause drug-induced movement disorders and lead to drug-induced Parkinsonism. ${ }^{4}$ This cluster of symptoms is commonly referred to as extrapyramidal syndrome.

Drug-induced Parkinsonism can be easily misdiagnosed as Parkinson's disease as the clinical features of these two conditions are indistinguishable. Clinical features common to both disorders include bradykinesia, rigidity, resting tremor and movement disorders. To distinguish between the two disorders, a DAT scan was ordered in this case. DAT imaging is useful for diagnosing presynaptic Parkinsonism, as dopamine uptake is significantly decreased in Parkinson's disease, and this helps to differentiate it from postsynaptic blockage by drug-induced Parkinsonism.

\section{TREATMENT}

The patient was withdrawn from akathisia-inducing drugs. Both olanzapine and escitalopram were withdrawn. However, the patient's symptoms of inner restlessness and inability to sit still did not improve. Hence, doctors proceeded in prescribing adjunctive medication. Propranolol was prescribed at $80 \mathrm{mg} /$ day orally but did not improve symptoms after several weeks of trial. Benzodiazepines such as clonazepam were also used at $1 \mathrm{mg} /$ day orally with clinically insignificant improvements. Lastly, other agents such as clonidine up to $0.15 \mathrm{mg} /$ day orally were used with minimal improvements in the patient's symptoms.

After exhausting all first-line options supported by primary research, both the physician and patient agreed to try a series of electroconvulsive therapy (ECT) treatments. After 12 ECT sessions, the patient had enormously significant improvements in depressive symptoms and to the surprise of the medical team, the symptoms of akathisia had completely disappeared. The patient achieved remission from feelings of inner restlessness, inability to sit still and depressed mood. The patient experienced great improvement and was able to return to normal functioning following an extremely distressing and unsuccessful period of failed treatments. This report provides evidence of a case of non-refractory symptoms of both depression and drug-induced akathisia that substantially improved following ECT with no residual adverse effects. Following ECT, the patient was prescribed $75 \mathrm{mg}$ of clomipramine to prevent depression relapse.

\section{OUTCOME AND FOLLOW-UP}

Two years after treatment with ECT, the patient remains in remission and is functioning normally in social, occupational and family circumstances. The patient has no residual symptoms and no adverse effects from ECT.

The patient is now on $75 \mathrm{mg}$ of clomipramine and experiences no side effects. 


\section{DISCUSSION}

Akathisia is a very distressing condition that is known to increase suicidal ideation and impulsive behaviour. In many cases, the symptoms of akathisia can be more distressing than the underlying mental health disorder itself. It is often underdiagnosed and symptoms are attributed to underlying anxiety or mental health disorders. As a result, clinicians continue prescribing psychiatric drugs that can make the symptoms of akathisia worse and lead to a vicious cycle. It is therefore of great importance that clinicians maintain a degree of high suspicion and recognise symptoms early in their presentation to prevent complications. Various reports have estimated the occurrence rate of SSRI-induced akathisia to range from $9.8 \%$ to $45.1 \% .^{5}$

Previous case studies have also presented the emergence of akathisia following the administration of psychiatric drugs. SSRI-induced akathisia is suggested by several case reports. ${ }^{6} 7$ A case of paroxetine-induced akathisia has been reported. ${ }^{6}$ A case of sertraline-induced akathisia leading to suicidal attempts has also been reported. On withdrawal of the antidepressant, akathisia completely resolved. ${ }^{7}$ This further emphasises the importance of recognising the symptoms of akathisia early to avoid negative outcomes and the deterioration of the mental state of patients. Furthermore, akathisia has been reported with the use of SNRIs, although more rarely. ${ }^{8}$

It is therefore evident that both SSRIs and antidopaminergic drugs may occasionally induce extrapyramidal side effects and akathisia. The proposed mechanism of this is the serotonergically mediated inhibition of the dopamine system. Concurrent antidopaminergic therapy may predispose patients to these effects. 9 The potential risks can be minimised by preventing unnecessary and fast dose increments. Physicians should be aware of the emergence of these severe negative effects when introducing new drugs to the current drug regimen of patients, especially when psychiatric drugs are combined. It is important to note that the development of akathisia after the combination of escitalopram, which is one of the most selective serotonin reuptake inhibitors, and olanzapine in this case support the theory of serotonergically mediated inhibition of dopamine which was likely augmented by concurrent antipsychotic use, further blocking dopamine receptor stimulation. This mechanism persisted even after the withdrawal of the causative agents when the SPECT scan was carried out, supporting the diagnosis of tardive akathisia.

The treatment of akathisia is challenging and, in some cases, as we have seen with this patient, akathisia does not remit after the withdrawal of the causative agent. This type of tardive akathisia is extremely challenging to treat, and there are no treatment guidelines in literature to guide clinicians. Evidence is limited to a small number of case studies on tardive akathisia. Two case reports suggest the successful treatment of tardive akathisia with moclobemide and clonidine. ${ }^{1011}$

Our case study is one of the first papers to provide evidence of the successful remission of both tardive akathisia and depressive symptoms following treatment with ECT. If confirmed in further cases, these findings can provide a basis for well-designed randomised controlled trials on the efficacy of treatments such as ECT on movement disorders and extrapyramidal symptoms.
Furthermore, this case study provides valuable evidence to clinicians who remain unaided in the management of tardive akathisia in patients with depression.

\section{Learning points}

- Underdiagnosis of tardive akathisia is common in clinical practice. Instead, symptoms of inner restlessness and the inability to sit still are attributed to underlying mental health disorders and anxiety.

- Consequently, physicians prescribe further medications to treat the assumed underlying mental health problems. Many of the drugs prescribed can induce and further exacerbate akathisia.

- This report serves to increase awareness of this condition and aims to help doctors tackle similar clinical scenarios in the future.

- We therefore present a case of tardive akathisia complicated by treatment-resistant depression that completely resolved following a series of electroconvulsive (ECT) sessions.

- This case study presents a well-documented treatment intervention, ECT, used effectively in a new clinical situation.

Contributors As the sole author, I approve the version to be published and agree to be accountable for all aspects of the work in ensuring that questions related to the accuracy or integrity of any part of the work are appropriately investigated and resolved.

Funding The authors have not declared a specific grant for this research from any funding agency in the public, commercial or not-for-profit sectors.

Competing interests None declared.

Patient consent for publication Obtained.

Provenance and peer review Not commissioned; externally peer reviewed.

Open access This is an open access article distributed in accordance with the Creative Commons Attribution Non Commercial (CC BY-NC 4.0) license, which permits others to distribute, remix, adapt, build upon this work non-commercially, and license their derivative works on different terms, provided the original work is properly cited and the use is non-commercial. See: http://creativecommons.org/ licenses/by-nc/4.0/

\section{REFERENCES}

1 Bromet E, Andrade LH, Hwang I, et al. Cross-national epidemiology of DSM-IV major depressive episode. BMC Med 2011;9:90.

2 Al-Harbi KS. Treatment-resistant depression: therapeutic trends, challenges, and future directions. Patient Prefer Adherence 2012;6:369.

3 Basu B, Gangopadhyay T, Dutta N, et al. A case of akathisia induced by escitalopram: case report \& review of literature. Curr Drug Saf 2014;9:56-9.

4 Shin H-W, Chung SJ, Parkinsonism D-IJ Clin Neurol 2012;8:15.

5 Chelben J, Strous RD, Lustig M, et al. Remission of SSRI-induced akathisia after switch to nefazodone. J Clin Psychiatry 2001;62:570-1.

6 Bonnet-Brilhault F, Thibaut F, Leprieur A, et al. A case of paroxetine-induced akathisia and a review of SSRI-induced akathisia. Eur Psychiatry 1998:13:109-11.

7 Nepal H, Black E, Bhattarai M. Self-Harm in Sertraline-Induced Akathisia. Prim Care Companion CNS Disord 2016;18.

8 Grover S, Valaparla VL. Venlafaxine induced akathisia: a case report. Indian J Pharmacol 2014;46:660.

9 Lane RM. SSRI-induced extrapyramidal side-effects and akathisia: implications for treatment. J Psychopharmacol 1998;12:192-214

10 Ebert D, Demling J. Successful treatment of tardive akathisia with moclobemide, a reversible and selective monoamine-oxidase-A inhibitor. A case study. Pharmacopsychiatry 1991:24:229-31.

11 Amann B, Erfurth A, Grunze H. Treatment of tardive akathisia with clonidine: a case report. Int J Neuropsychopharmacol 1999;2:151-3. 
Copyright 2019 BMJ Publishing Group. All rights reserved. For permission to reuse any of this content visit https://www.bmj.com/company/products-services/rights-and-licensing/permissions/

BMJ Case Report Fellows may re-use this article for personal use and teaching without any further permission.

Become a Fellow of BMJ Case Reports today and you can:

- Submit as many cases as you like

- Enjoy fast sympathetic peer review and rapid publication of accepted articles

Access all the published articles

- Re-use any of the published material for personal use and teaching without further permission

Customer Service

If you have any further queries about your subscription, please contact our customer services team on +44 (0) 2071111105 or via email at support@bmj.com.

Visit casereports.bmj.com for more articles like this and to become a Fellow 